\title{
Investigation of Axial Flux In-Wheel Motor Performances Based on Multiphysics Analysis
}

\author{
Haishi DOU ${ }^{1 a}$, Youtong ZHANG ${ }^{*}$, Tao $\mathrm{LI}^{1}$ and Qiang AI ${ }^{1}$ \\ ${ }^{1}$ Laboratory of Low Emission Vehicle, Beijing Institute of Technology
}

\begin{abstract}
The axial flux with amorphous alloy stators has the virtues of high power density, high torque density, compact structure. But specific to the disadvantage of restricted space of in-wheel, the compact axial flux in-wheel motor was proposed in this paper. The in-wheel motor's performance affects the dynamic and security of electric vehicles directly. And the electromagnetic loss has a significant impact on in-wheel motor performance. To demonstrate the influence of electromagnetic loss on the thermal behavior of the machine, thermal analyses employing magneto-thermal coupling simulations have been performed. Then the experimental prototype was manufactured and tested. The simulation of the output power model was verified by test value, proving that the magneto-thermal coupling simulation is feasible. Therefore, this design technique provides a reference for the in-wheel motor structure.
\end{abstract}

\section{Introduction}

With the demand for energy conservation and environmental protection, axial flux permanent magnet synchronous machines (PMSM) applied in electric vehicles (EVs) have attracted extensive attention all over the world $[1,2]$. Since axial flux PM motor has more advantages over radial permanent magnet synchronous motor, which higher efficiency and less axial length are more suitable for electric vehicle in-wheel. On the contrary, be limited by the practical condition, in-wheel motor is in a sealed environment and compact space, and the permanent magnet is sensitive to thermal. The PMSM's properties are always restricted by heat generation and dissipation, so elevated temperature distribution has a significant impact on in-wheel motor performance. To further improve the power density and torque density of motor, numerous methods are researched such as non-dominated sorting genetic algorithm II for dual-structure permanent magnet machine [3] and supervised machine learning for sixphase PMSM [4].

Considering the small space in EVs in-wheel is in progress complex electric-mechanical energy conversion in a magnetic field and thermal field. The PMSM has a compact structure and high power density since the amorphous alloy is applied to magnetically permeable material that with the nature of smaller magnetic resistance, and makes it possible for lower temperature rising in-wheel. An axial-flux PMSM is investigated in this paper, which mathematical model of electromagnetic loss to express thermal transformation was founded to illustrate the progress of temperature rising. Then the ANSYS workbench was employed to performed magneto-thermal coupling simulations, which consistent with the actual test of temperature rising approximately.

\section{Loss of Axial Flux Permanent Magnet Synchronous Motor}

The application in EVs of low power in-wheel motor, the structure, and physical winding unit of axial-flux PMSM is shown in Figurel and 2. The axial flux PMSM adopting 3-phase winding, 24 pole, and 27 slots, the fraction slot concentrated wing which has the advantages of smaller copper loss, more stable torque, and higher torque density. The permanent magnets are at both ends of rotor cores, and rotor cores are fixed at the outer rotor and rotor bracket which are to form double rotors. The winding coils are arranged around in the stator bracket and amorphous alloy inserts in the winding bracket. Simultaneously, copper wire twining on the wingding bracket to form a winding unit. In outer rotor has the structure of a thermal conductivity rib in which benefits for thermal dissipation naturally.

* Corresponding author: youtong@bit.edu.cn; Tel.: +86-10-6891-5013

a 3120195267@bit.edu.cn 


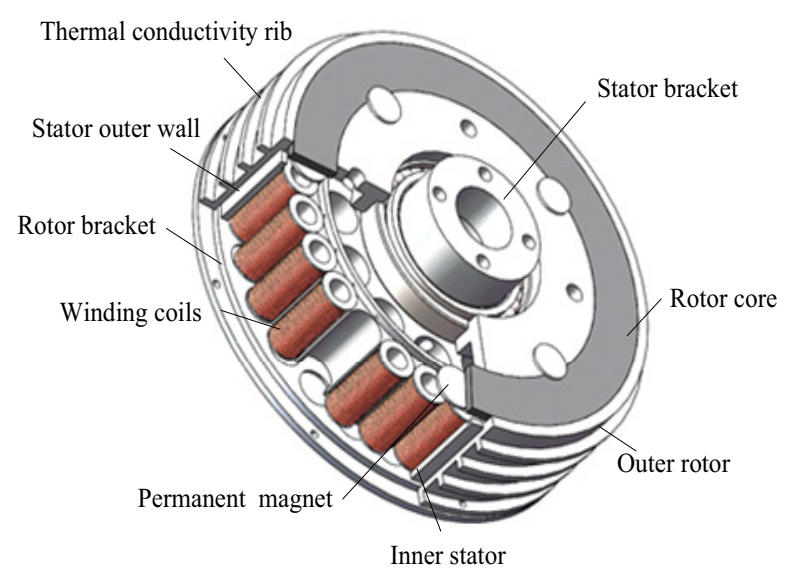

Figure 1. The structure diagram of permanent magnet synchronous motor

Winding coils Amorphous alloy

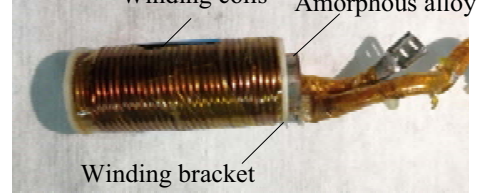

Figure 2. Physical winding unit

The electromagnetic loss result in PMSM's heat generation and the temperature rising, accurate calculation of electromagnetic loss is significant to forecast the temperature rising. The electromagnetic loss mainly consists of iron loss $P_{\mathrm{Fe}}$, eddy loss $P_{\mathrm{Mag}}$, copper loss $P_{\mathrm{Cu}}$, and mechanical loss $P_{\mathrm{Me}}$ respectively. The iron loss generated in the stator, which amorphous alloy is composed, the evaluation expression for iron loss is given by

$$
P_{\mathrm{Fe}}=\left(K_{\mathrm{h}} f B_{\mathrm{m}}^{\alpha}+K_{\mathrm{e}} d^{2} f^{2} B_{\mathrm{m}}^{2}+K_{\mathrm{exc}} f^{1.5} B_{\mathrm{m}}^{1.5}\right) \mathrm{V}
$$

where $K_{\mathrm{h}}$ is coefficient of hysteresis loss and $f$ is the alternating frequency of magnetic field; $B \mathrm{~m}$ is maximum magnetic density; $K_{\mathrm{e}}$ is coefficient of eddy loss; $K_{\text {exc }}$ is coefficient of additional eddy current; $d$ and V are active thickness and volume of Amorphous alloy separately; a is a constant.

The eddy loss in PMSM is expressed in [5]

$$
P_{\text {Mag }}=\sum_{n}\left\{\int_{M \mathrm{ag}} \frac{\left|J_{\mathrm{n}}\right|^{2}}{2 \sigma} d \mathrm{v}\right\}
$$

where $P_{\text {Mag }}$ is eddy loss; $J_{\mathrm{n}}$ is the current density of PMSM; $\sigma$ is the conductivity of PMSM; $n$ is the number of permanent magnet and $\mathrm{v}$ is a single volume of a permanent magnet.

In most cases, the frequency of the current in PMSM is under $1 \mathrm{kHz}$, so the copper loss is calculated by equation (3) on account of additional winding loss is ignored.

$$
P_{\mathrm{CU}}=N I^{2} R
$$

where $P_{\mathrm{Cu}}$ is copper loss; $N$ is the number of phases; $I$ is phase current; $R$ is phase resistant.

Further, the total loss of PMSM can be written as

$$
P_{\text {loss }}=P_{\mathrm{Fe}}+P_{\mathrm{Mag}}+P_{\mathrm{CU}}+P_{\mathrm{Me}}
$$

where the $P_{\mathrm{Me}}$ is a mechanical loss. Comparing with other mechanical loss $P_{\mathrm{Me}}$ is in small proportion, this is ignored in this paper. Furthermore, according to the law of heat transfer winding's temperature is expressed in

$$
Q=c m\left(T_{2}-T_{1}\right)
$$

where the $\mathrm{Q}$ is the heat absorbed or released, $c$ and $m$ are specific heat capacity, the active weight of the material, respectively. $T_{2}$ and $T_{1}$ are terminal temperature and ambient temperature separately. This paper considers the winding coils' electromagnetic loss that the copper loss and eddy loss are included. On account equation (5) do not consider thermal coupling with different materials, so the winding coils' electromagnetic loss in this paper is presented as follow:

$$
\begin{aligned}
& Q_{1}=P_{\mathrm{Mag}} \mathrm{t} \\
& Q_{2}=P_{\mathrm{CU}} \mathrm{t}
\end{aligned}
$$

where $\mathrm{Q}_{1}, \mathrm{Q}_{2}$ are heating from eddy loss and copper loss of winding coils, and $t$ is the time during the experience.

In an unsteady temperature field, the heat generated or absorbed in winding coils converter to temperature rising ultimately. The magneto field and thermal field collectively affect the in-wheel motor's temperature rising, and winding coils of the in-wheel motor is core component, hence investigating temperature field drawn support from an analytic formula.

\section{Electromagnetic loss simulation based on magneto-thermal coupling analysis}

Before analyzing magneto-thermal coupling simulations, three dimensions (3-D) model of axial-flux PMSM was established, then the 3D model was imported into Maxwell Ansoft 19.2 (ANSYS, Inc., Canonsburg, PA, USA) to calculate the different components of electromagnetic loss. With the conditional of middle speed, the electromagnetic loss was regarded as the heat sources; then imported into Ansys Workbench 19.2. (ANSYS, Inc., Canonsburg, PA, USA) to carry out a mechanical transient thermal analysis. Before analyzing electromagnetic loss, hexahedral hot were performed based on the equivalent thermal network method[6]. The electromagnetic loss of different composition cannot define temperature distribution correctly, in this research, 3D finite element magneto-thermal coupling analysis was applied along Maxwell Ansoft with Ansys Workbench to conduct coupling simulation model for electromagnetic and temperature field for in-wheel motor[7]. And thermal power of electromagnetic loss was imported as a load of the heat source into the temperature field, and electromagnetic loss was calculated in Maxwell Ansoft ahead of time, which the flux density distribution of stator core is shown in Figure 3 . The thermal power was generated by electromagnetic loss then imported into the temperature field model of transient thermal. 

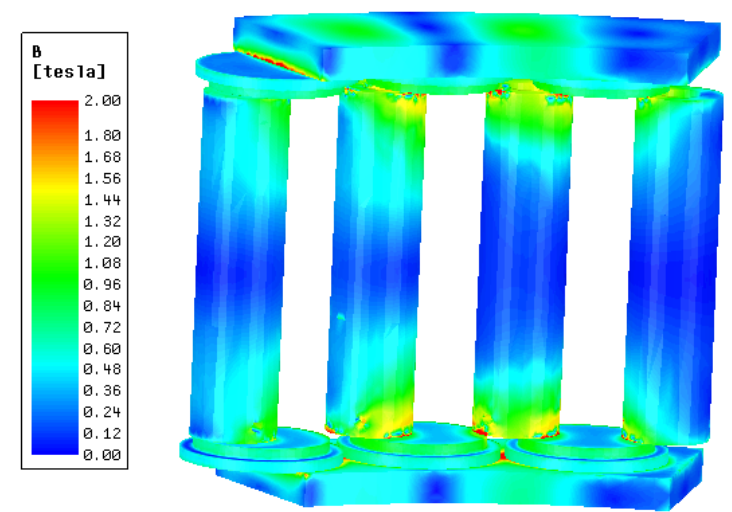

Figure 3. Flux density distribution of stator core

The parameters of the experimental prototype of the in-wheel motor are shown in Table 1. The material of permanent magnet is $\mathrm{N} 38 \mathrm{UH}$; the material of stator core and rotor core are DT4 and amorphous alloy respectively. The step end time is set as $1800 \mathrm{~s}$. And putting to use auto time-stepping, controlled by a program, and the output revolving speed is $50 \mathrm{r} / \mathrm{min}$. The Ansoft software is used for magnetic field simulation, in which the inputs to system is three-phase AC power the prototype outputs speed of $50 \mathrm{r} / \mathrm{min}$. Afterward, the electromagnetic loss was regarded as a heat source in internal that generation heat distributing on each component. Then the heat source was imported into the mechanical transient thermal field.

The prototype is circumferentially symmetrical, to calculate conveniently and accurately, which one-eighth analyzing model is conducted in the thermal field. The following signs of progress are the general step of finite element analysis, Therefore, the temperature distribution is presented in Figure 4.

Table 1. Technical parameters of in-wheel motor and winding

\begin{tabular}{|c|c|c|}
\hline Parameters & Symbol & Value \\
\hline length of the air gap & $\mathrm{g}$ & $1 \mathrm{~mm}$ \\
\hline $\begin{array}{l}\text { The thickness of the } \\
\text { permanent magnet }\end{array}$ & $L \mathrm{~m}$ & $4 \mathrm{~mm}$ \\
\hline Axial length & $\mathrm{La}$ & $86 \mathrm{~mm}$ \\
\hline $\begin{array}{l}\text { Rotor outer } \\
\text { diameter }\end{array}$ & $D a$ & $266 \mathrm{~mm}$ \\
\hline $\begin{array}{l}\text { Rotor inner } \\
\text { diameter }\end{array}$ & $D \mathrm{i}$ & $206 \mathrm{~mm}$ \\
\hline $\begin{array}{l}\text { The axial length of } \\
\text { the winding }\end{array}$ & $\mathrm{Cl}$ & $55.4 \mathrm{~mm}$ \\
\hline $\begin{array}{l}\text { The radial thickness } \\
\text { of the winding }\end{array}$ & $M u$ & $3.2 \mathrm{~mm}$ \\
\hline
\end{tabular}

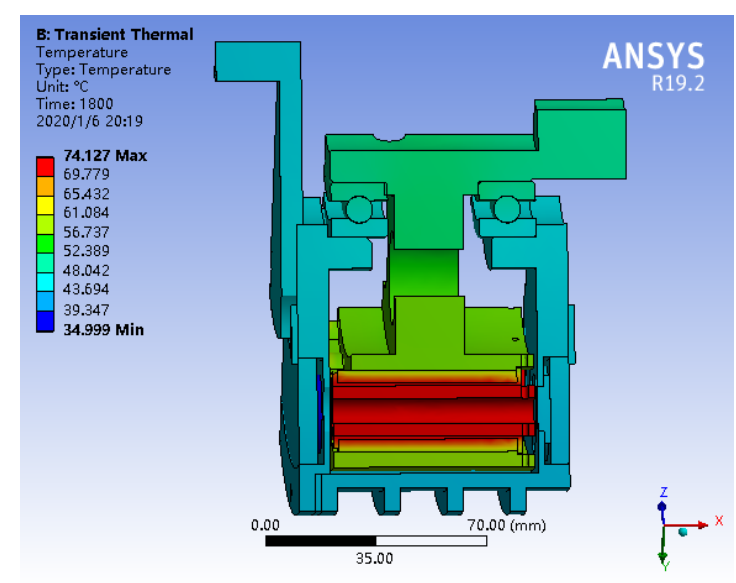

Figure 4. Temperature distribution in prototype motor

The heat of copper loss, iron loss, and eddy current loss mostly focus on the stator core, and the temperature declining along radial direction gradually easier than axial direction as a result of heat conduction and convection. As for cooling equipment, cooling water or oil is feasible in the space of the stator.

\section{Experimental verification}

The prototype experimental tests are implemental with the test bench as shown in Figure 5. The stator bracket was fixed on the test bench, on the other side, the output shaft was connected with the dynamometer through a coupling. The investigation exploited low rotation speed with $25 \mathrm{r} / \mathrm{min}$ and middle rotation speed with $50 \mathrm{r} / \mathrm{min}$.

The thermocouple sensor was embedded in the inwheel motor and fix on a different component. When the in-wheel motor is operating at an average torque of 22.4 $\mathrm{N} \cdot \mathrm{m}$ and revolving speed of $50 \mathrm{r} / \mathrm{min}$. The transient state analysis was performed $1800 \mathrm{~s}$, in the meantime the inner surface of the stator, air gap, winding coil and axial winding end temperature rising processing are shown in Figure 6. The ambient temperature is considered to be $25.1^{\circ} \mathrm{C}$.

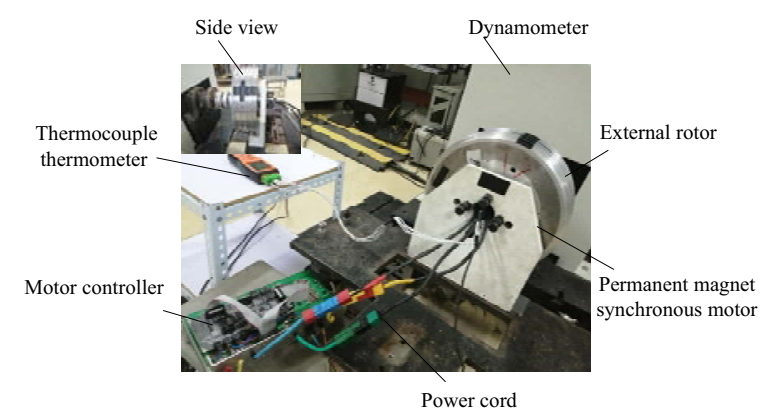

Figure 5. Prototype test bench of axial-flux PMSM 


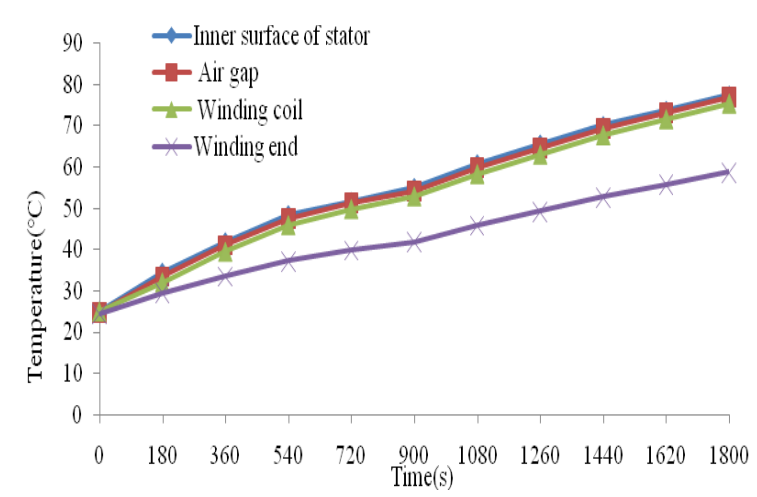

Figure 6. Prototype's temperature rising of different structure From Figure 8, the following conclusions can be drawn. The components with the radial direction of temperature trend to slight changed, meanwhile the heat of windings' axial direction is apt to affect by surrounding environment, so the measured temperature of winding ends are little lower than that of the middle part. So the cooling device such as cooling water or oil should be along with radial direction arranged. The iron loss, eddy loss, and copper loss transfer to heat in the stator tooth of the in-wheel motor. As a consequence, the inner surface of the stator assembled more heat.

\section{Discussion and Conclusions}

Specific to the electric vehicles have applied universally, with restricted space in in-wheel, and the demanding of the axial-flux in-wheel motor was proposed in this paper.

(1) In this paper, the axial flux in-wheel motor was investigated, in which the mathematical model of electromagnetic loss to express thermal transformation was founded to illustrate the progress of temperature rising.

(2) The prototype of the in-wheel motor was modeled in Ansoft Maxwell to build the electrical parameters in the magnetic field. Then the ANSYS workbench was employed to performed magneto-thermal coupling simulations to explain the temperature field distribution in an in-wheel motor.

(3) A $1.5 \mathrm{~kW}$ in-wheel motor prototype was designed and manufactured. The temperature rising of the inwheel motor is investigated and consistent with the simulation result approximately, in which the magneto-thermal coupling simulation method is validated.

\section{References}

1. Zhao, J. Liu, W. Li, B. (2015) Investigation of Electromagnetic, Thermal and Mechanical Characteristics of a Five-Phase Dual-Rotor Permanent-Magnet Synchronous Motor. Energies. 8:9688-9718.

2. Yang, Y. Zhang, Y. Tian, J. Zhang, S. (2018) Research on a Plug-In Hybrid Electric Bus Energy Management Strategy Considering Drivability. Energies. 11.
3. Ma, Y. Ching, TW. Fu, WN. Niu, SX. (2019) MultiObjective Optimization of a Direct-Drive DualStructure Permanent Magnet Machine. Ieee Transactions on Magnetics. 55:4.

4. Dhulipati, H. Ghosh, E. Mukundan, S. Korta, P. Tjong, J. Kar, NC. (2019) Advanced Design Optimization Technique for Torque Profile Improvement in Six-Phase PMSM Using Supervised Machine Learning for Direct-Drive EV. IEEE Trans Energy Convers. 34:2041-2051.

5. Kim, SC. (2013) Thermal Performance of Motor and Inverter in an Integrated Starter Generator System for a Hybrid Electric Vehicle. Energies. 6:6102-6119.

6. Guo, YG. Zhu, JG. Wu, W. (2005) Thermal analysis of soft magnetic composite motors using a hybrid model with distributed heat sources. Ieee Transactions on Magnetics.41:2124-2128.

7. Wang, S. Guo, YC. Cheng, G. (2017) Performance Study of Hybrid Magnetic Coupler Based on Magneto Thermal Coupled Analysis.10:1148. 